\title{
EDITORIAL
}

\section{LIVE LONG AND PROSPER}

\author{
By SHANe Whelan
}

\section{Actuarial Escape Velocity}

The single greatest achievement of previous generations has been to propagate life. The second greatest achievement, arguably, has been to pass on the means and knowledge to lengthen the lifespan of future generations. The latter claim is supported by 'quality of life' indices which, by construction, must weigh the relative significance of those factors that are known to affect the quality of life. The Economist Intelligence Unit's Quality of Life Index, perhaps the best constructed of such indices, gives life expectancy at birth a weighting of $19.0 \%$, marginally higher than GDP per person (Economist, 2004) while the United Nation's Human Development Index gives life expectancy an equal weight (at 33\%) with material well-being (United Nations Development Programme, 2005). So, it would appear, the most valued gift to the newborn generation is the means to prolong life. But this is ultimately a value judgement: what price would you pay for an extra year of life for yourself or a loved one?

England and Wales, in a pattern typical of developed economies, increased life expectancy at birth for both males and females by an average of 0.3 years with the passage of each calendar year over the twentieth century (see Figure 1). Indeed, the almost linear increase in life

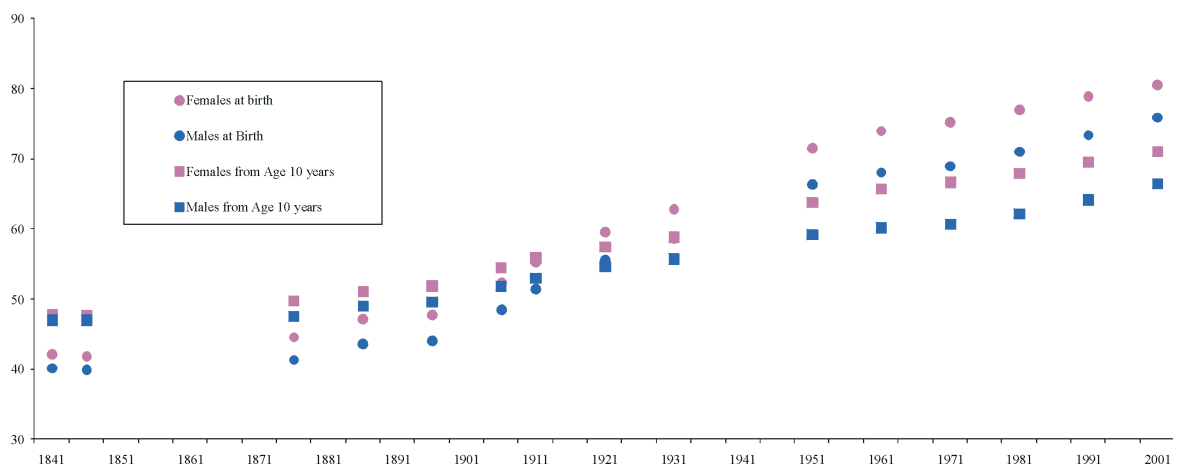

Source: Period Life Expectancies from English Life Tables 1 to 16

Figure 1. Life Expectancy at Birth and at Age 10 Years, Males \& Females, England \& Wales. 1841-2001 
expectancies over the last century and a half provides a reassuring regularity that suggests a partial mastery of manipulating mortality. Such success has encouraged some to ponder whether the earliest dream of our race - the dream of immortality as reflected in myths and religions might be achievable in the form of an indefinite lifespan. De Grey has coined the term 'actuarial escape velocity' for the rate of mortality improvement where a person's remaining life expectancy does not decrease with the passage of time (de Grey, 2004). So what are the means to prolong life and can increases in life expectancies be accelerated from the current rate to the mythical rate of at least 1 year added with the passage of each calendar year?

\section{Joining Forces on Mortality and Longevity}

The Actuarial Profession played host to a conference, Joining Forces on Mortality and Longevity, that brought biomedical and health researchers together with demographers and actuaries for a couple of days in October 2009 at the Royal College of Physicians in Edinburgh. The Queen Mother Conference centre, in which the plenary sessions were held, was singularly apt to discuss longevity, noted the Conference Chairman, Professor Tom Kirkwood, as the Queen Mother was 101 years old at the time of her death in 2002.

The conference was planned by the Mortality Research Steering Group (Macdonald, 2008) around three inter-related themes: drivers of change in longevity, how successive cohorts differ and why, and the connections between aggregate population mortality and individual risk characteristics. Their careful planning was rewarded by the participation of some of the leading authorities in this area (as evidenced by the list of authors in this issue) and, perhaps equally significantly, by the dialogue and the crossfertilisation of ideas. This supplement to the British Actuarial Journal records a selection of the papers presented at the conference.

\section{The First Five Papers in this Issue}

So what, according to the assembled experts, is the secret of prolonging life? The issue begins with Diana Kuh et al.'s comprehensive Review of Life Time Risk Factors for Mortality. This paper marshals research on such factors as environment, lifestyle, body size, physical ability and cognitive function to show how each alters the mortality experience of individuals not just when currently exposed to such factors but at times long after exposure - with linkages reported between elevated mortality late in life and early life experiences. In particular, in section 6, they quantify the extent of the relationship between lifestyle choices and mortality: smoking, alcohol intake, physical inactivity, and poor diet are shown to increase mortality fourfold, with smoking alone doubling mortality rates over a broad range of ages. Since over one-third of deaths in the developed world are attributable to 
lifestyle choices, it points to the potential for individuals to extend significantly their own longevity.

The importance of individual risk characteristics in mortality disposes one to seek cohort influences in population mortality trends. Carol Jagger et al. take up this theme in their paper, Cohort Differences in Mortality and Morbidity. They review the papers presented at the conference on the cohort theme and, in addition, give an overview of research that suggests that the increase in longevity at advanced ages over recent decades is associated with a postponement of disability. In short, the increases in life expectancies witnessed in recent decades are, largely, increases in healthy life expectancies.

Next follows papers that provide evidence for the cohort effect at aggregate population levels. David Forfar reminds us of the statistical evidence in the populations of Scotland as well as England and Wales and shows the consequences of incorporating a cohort effect in mortality projections. Alison O'Connell and Kim Dunstan report finding evidence that the UK 'golden generation' has brought along their mortality improvement as emigrants to New Zealand. Maria Reinert-Azambuja highlights the complex connections that could be posited to exist when early life experiences can impact later life mortality, with her speculative paper suggesting a link between heart disease late in life and exposure to influenza early in life.

\section{Do Individual Risk Characteristics Add to a Cohort Effect in Population Mortality?}

It would appear conclusive from the first five papers that well-known individual risk characteristics of mortality are manifest in population mortality. Accordingly, population mortality is perhaps best analysed and projected on a cohort basis (as opposed to a calendar year basis) as each cohort's life experiences has been so different over the twentieth century. Of course, this has been a major theme explored in this Journal over the last decade (see, for example, Willets, 2004; Willets et al., 2004; Richards et al., 2006; Richards et al., 2007). In fact, as many authors in this issue point out, such a cohort analysis and its rationale was first proposed as early as 1927 by the actuary Victor Derrick in a predecessor of this Journal (Derrick, 1927). Population mortality projections and mortality projections for many actuarial purposes have incorporated the so-called 'cohort effect' for a number of years now although, curiously, the cohort effect does not seem to be manifest in many countries outside of the British Isles and Japan.

Adding a parameter for year of birth as a proxy for cohort effects (even with the restriction of some level of smoothness from one birth year to the next), alongside the usual age and calendar year parameters, runs the risk of over-parameterising the mortality model. Over-parameterised models produce spuriously good in-sample fits, unstable projections, and too narrow confidence intervals associated with the projections. Accordingly, the introduction of another factor for each cohort, exemplified in David Forfar's 
paper in this issue, is resisted by some who remain unconvinced that the evidence is sufficiently compelling to move from the parsimony of the traditional model — with just age and calendar year parameters and the proviso that the population modelled is fairly stable over time with respect to known significant mortality drivers (e.g. gender, smoking status, etc).

Mike Murphy's paper, The 'Golden Generations' in Historical Context, challenges the 'cohort effect' and how it is currently modelled. He attempts to clarify what is meant by the cohort effect and summarises the challenges with modelling it statistically. He points out that the pattern observed in UK mortality statistics is not incompatible with a period effect. Using stylised modelling, he attempts to identify the most likely candidate from the five main hypotheses that have been advanced to date, ranging from the simple suggestion of a change in smoking patterns within the population over time to the more nebulous hypothesis that it arises from medical and welfare advances. Though more work is needed, it appears that the observed 'cohort effect' might simply be accounted for by changing smoking patterns and that, rather than a 'golden generation', what we are observing could be simply a pattern in population mortality arising when one generation is succeeded by another generation comprising fewer smokers. In short, he suggests that the observed 'cohort effect' is not reflecting individual mortality patterns (i.e., it does not reflect changing mortality of the average person in the population) but the changing mix of two separate populations within the overall population that have a material mortality differential.

To Mike Murphy's challenge must be added some general observations that also suggest that introducing a parameter for each year of birth alongside age in mortality models is too prolific, too much opposed to Occam's dedicate. First, we must acknowledge, as the original discoverer of the UK 'cohort effect' pattern did, that it was observed in the data during an exploratory analysis before it was hypothesised (Office of Population Censuses and Surveys, 1995). To use the data to suggest the hypothesis to test on the same data is not statistics but data-mining and, accordingly, the p-value of such tests of a cohort effect must be adjusted significantly downward. In short, one cannot rely on the reported statistical significance of the effect. Second, the so-called cohort effect is telling us little that we did not already know. Mortality improvements, in the UK and elsewhere in the developed world, were well-known to be concentrated at the early ages early in the twentieth century and, from about the 1970s mortality improvements began to be detected at later ages (a pattern described as the 'aging of mortality improvements', Wilmoth, 1997). The new insight from the cohort effect is then to draw a line from young adult ages to late middle ages and suggest the uniqueness of the mortality experience of particular cohorts. But the main causes of death in young adults and early middle age are accidents and injuries, so it is difficult to make a plausible case that trends in mortality over these years of age are linked to year-of-birth rather than age. In 
particular, for the 'golden generation' born around 1931, their twenties were in the austere and rationed 1950s which did not afford the same opportunities for such risk exposure - English Life Table 12 (Table C, p6) shows the relative fall in mortality across ages for both males and females was highest at age 25 years over the 1950s.

It is potentially a grave error to generalise from a unique set of circumstances to build models for future mortality that too closely capture past mortality patterns. Observations from mortality patterns over diverse environments suggest that the extra year-of-birth parameter has a low level of explanatory power in population mortality. Three general observations might be cited to caution the introduction of the year-of-birth parameter alongside age: (i) the convergence between East and West German mortality rates following reunification; (ii) the difficulty in detecting lasting impact on mortality after the population experience an acute trauma such as a famine; and (iii) the suspicious lack of a cohort effect in other developed economies. It is worthwhile to elaborate on point (i) and point (ii).

The key observation (originally made by Vaupel et al., 2003) comes from the rapid convergence of mortality rates at advanced ages following the reunification of Germany in 1990. Figure 2 shows the convergence of

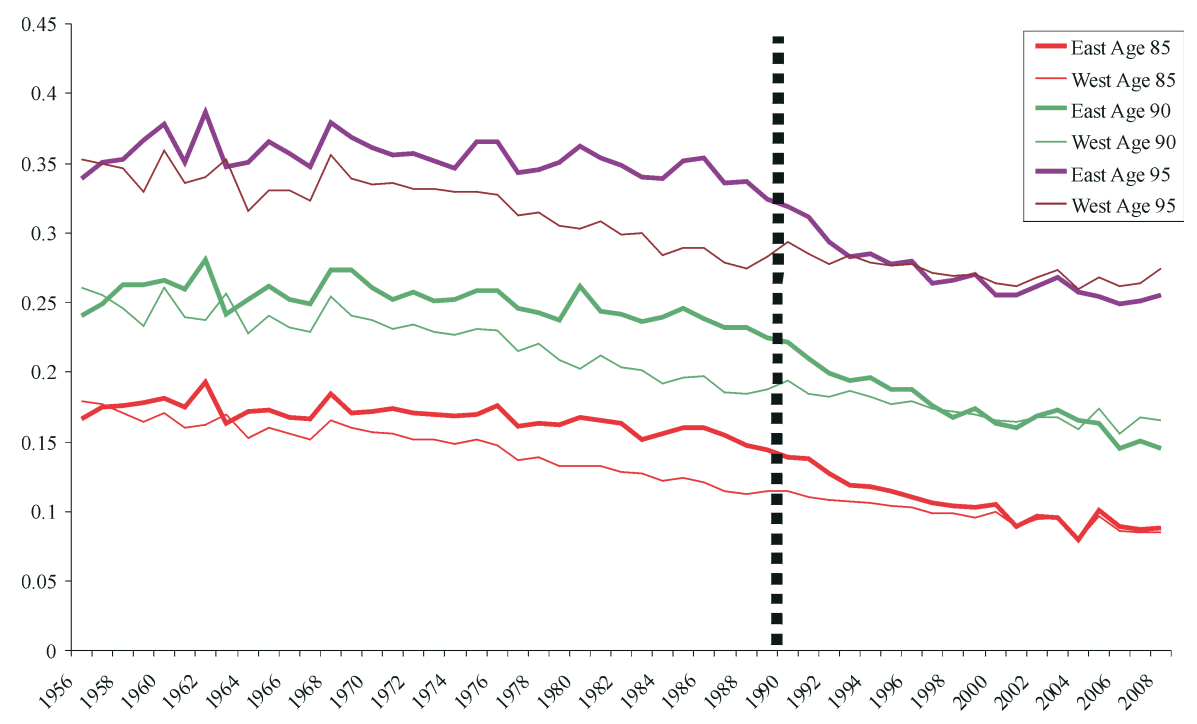

Source: Mortality rates sourced from www.mortality.org

Figure 2. Convergence of Mortality Rates at Advanced Ages following German Reunification in 1990: Mortality Rates at Fixed Ages Tracked over Calendar Years 


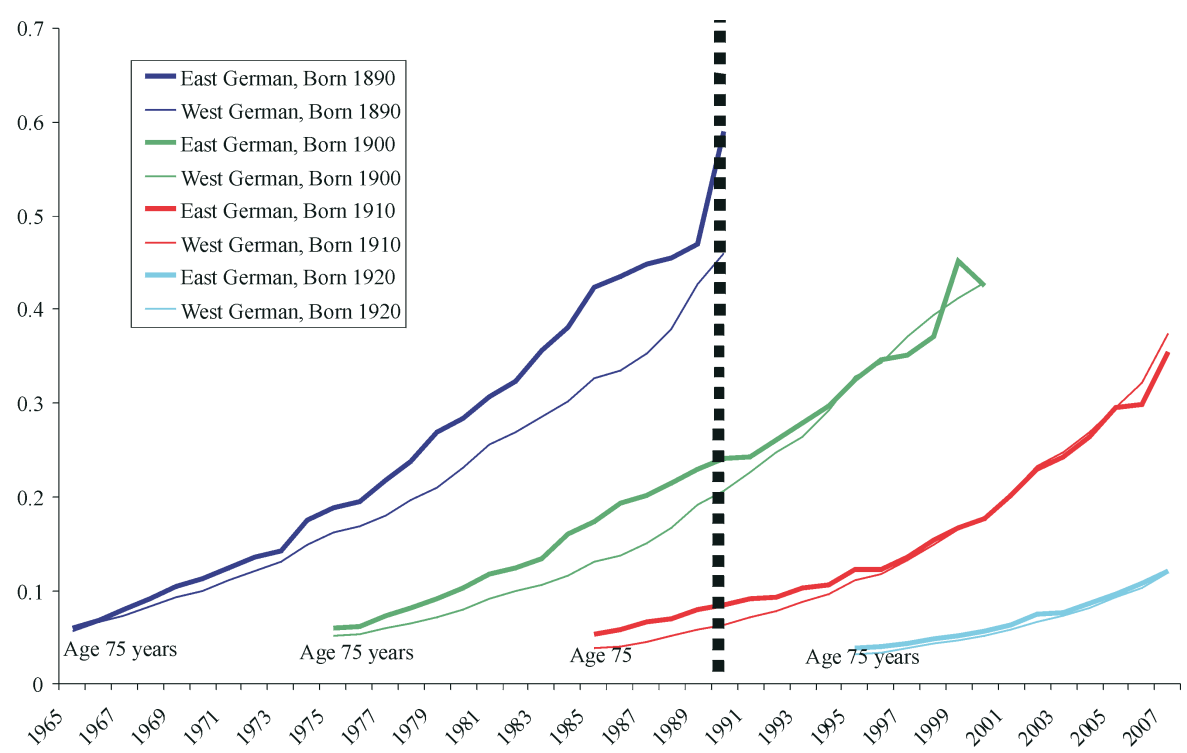

Source: Mortality Rates sourced from www.mortality.org

Figure 3. Convergence of Mortality Rates at Advanced Ages following German Reunification in 1990: Mortality Rates Tracked By Cohort (Fixed Year of Birth)

mortality rates at select advanced ages by calendar year and Figure 3 highlights the convergence of mortality rates between different birth cohorts after reunification. These figures make the case that mortality differentials need not persist even at advanced ages, even after a near-lifetime lived under quite different conditions with quite different mortality pertaining. Age and calendar year effects appear to dominate with apparently no lasting effect of past lifetime.

So, from the German experience and controlled studies in other species (e.g., Mair et al., 2003; Carey, 2003), one could form the hypothesis that a chronic exposure to relatively poor environment appears to have no lasting effect (after a select period) once the subject is removed from that environment. The hypothesis stated in its most general form applies equally to, say, smoking, diet, alcohol (although the select period will vary for each). However, the hypothesis underlying Maria Reinert-Azambuja's paper and supported by studies cited by several authors in this issue (such as Barker et al., 1989; Barker, 1994; Barker, 1998; Barker, 2001; Finch \& Crimmins, 2004; Gluckman \& Hanson, 2006; Gluckman et al., 2009) suggest that acute exposure to inimical conditions early in life can manifest later in life through 
elevated mortality. The evidence from Germany is not contradictory to this hypothesis as, of course, Germany was also unified when the cohorts above were born.

We need further evidence to support the hypothesis of the transitory impact on mortality risk of deleterious conditions. To my mind, evidence is provided in the difficulty of detecting a lasting impact on population mortality after the population experiences an acute trauma such as a famine. Mike Murphy's paper cites research findings that cohorts that were born in famine conditions, such as the Finnish Famine of 1866-68 or the Siege of Leningrad in 1941-43 or the Dutch Winter of Hunger of 1944, do not have appreciably higher mortality later in life. We can add to that list the Great Irish Famine of 1845-49, on the basis of the following evidence.

The Great Irish Famine was one of the longest and worst famines in modern times (Ó Gráda, 2007, pp19-20 and Table 3), with an excess death rate of $12 \%$, compared to say, the $7 \%$ excess death rate of the Finnish Famine of 1866-68. During Famine times, starvation is only a relatively minor cause of death, the major causes being dysentery, diarrhoea, fevers and consumption, so the whole population is exposed to some degree to inimical mortality influences (for causes of death in Ireland during the famine, see Mokyr \& Ó Gráda, 2002; Ó Gráda, 2007). Mortality rates during the Famine years in Ireland was approximately double that during the preFamine years, a relationship that holds reasonably stable across both age and sex at least for those over age 4 years (Boyle \& Ó Gráda, 1986). Accordingly, famine times provide a grim test to see if exposure to such deleterious conditions at young ages has a discernible lasting impact on mortality.

Table $1 \mathrm{a}$ and $1 \mathrm{~b}$ show mortality rates in the area now identified as the Republic of Ireland. Rates highlighted in bold through a diagonal show the mortality rates of those who were born during the famine or were just one year old at the start of the famine. A study of the table reveals that the cohorts born just before or during the famine had, in later life, mortality very similar to the cohorts before and after them. So exposure to famine conditions early in life appears to leave no trace in later life mortality statistics.

Mike Murphy's paper challenges the impression building up over the first five papers in this issue that mortality improvements in the past, and therefore the appropriate method to project into the future, has been cohortbased, with the generally better environment lived through by successive generations taking less of a toll of the body and therefore increasing the body's durability. Equally compelling evidence, at a population level, can be amassed that mortality improvements in the past, and therefore the expected pattern in the future, is based primarily on calendar year effects, with mortality improvements relating to calendar year not year of birth. The reader will have to pass F. Scott Fitzgerald's test of a first-rate intelligence - 
Table 1a. Mortality rates of females in Ireland, post Great Famine of 1845-1849

Calendar year

$\begin{array}{ccccccc}\begin{array}{c}\text { Age } \\ \text { (years) }\end{array} & \underline{1871} & \underline{1882} & \underline{1891} & \underline{1901} & \underline{1911} & \underline{1926} \\ 7 & 0.0051 & 0.0048 & 0.0042 & 0.0047 & 0.0037 & 0.0025 \\ 12 & 0.0033 & 0.0033 & 0.0035 & 0.0036 & 0.0029 & 0.0020 \\ 17 & 0.0048 & 0.0050 & 0.0054 & 0.0054 & 0.0045 & 0.0038 \\ 22 & \mathbf{0 . 0 0 5 8} & 0.0063 & 0.0065 & 0.0061 & 0.0054 & 0.0049 \\ 27 & \mathbf{0 . 0 0 7 2} & 0.0077 & 0.0081 & 0.0073 & 0.0064 & 0.0058 \\ 32 & 0.0083 & \mathbf{0 . 0 0 8 9} & 0.0092 & 0.0085 & 0.0073 & 0.0060 \\ 37 & 0.0088 & \mathbf{0 . 0 0 9 4} & 0.0094 & 0.0095 & 0.0081 & 0.0068 \\ 42 & 0.0096 & 0.0104 & \mathbf{0 . 0 1 0 3} & 0.0107 & 0.0093 & 0.0080 \\ 47 & 0.0106 & 0.0120 & \mathbf{0 . 0 1 2 0} & 0.0120 & 0.0107 & 0.0095 \\ 52 & 0.0136 & 0.0159 & 0.0162 & \mathbf{0 . 0 1 5 7} & 0.0145 & 0.0132 \\ 57 & 0.0187 & 0.0225 & 0.0233 & \mathbf{0 . 0 2 2 0} & 0.0213 & 0.0192 \\ 62 & 0.0291 & 0.0338 & 0.0354 & 0.0331 & \mathbf{0 . 0 2 8 4} & 0.0274 \\ 67 & 0.0467 & 0.0515 & 0.0543 & 0.0505 & \mathbf{0 . 0 3 5 0} & 0.0375 \\ 72 & 0.0699 & 0.0752 & 0.0799 & 0.0751 & 0.0492 & 0.0543 \\ 77 & 0.1006 & 0.1068 & 0.1143 & 0.1098 & 0.0742 & \mathbf{0 . 0 8 0 6} \\ 82 & 0.1382 & 0.1487 & 0.1568 & 0.1551 & 0.1124 & \mathbf{0 . 1 1 5 7} \\ 87 & 0.1842 & 0.2046 & 0.2089 & 0.2143 & 0.1703 & 0.1622\end{array}$

Table 1b. Mortality rates of males in Ireland, post Great Famine of 18451849

Calendar year

$\begin{array}{ccccccc}\begin{array}{c}\text { Age } \\ \text { (years) }\end{array} & \underline{\mathbf{1 8 7 1}} & \underline{\mathbf{1 8 8 2}} & \underline{\mathbf{1 8 9 1}} & \underline{\mathbf{1 9 0 1}} & \underline{\mathbf{1 9 1 1}} & \underline{\mathbf{1 9 2 6}} \\ 7 & 0.0051 & 0.0044 & 0.0037 & 0.0037 & 0.0032 & 0.0019 \\ 12 & 0.0029 & 0.0027 & 0.0026 & 0.0026 & 0.0022 & 0.0012 \\ 17 & 0.0050 & 0.0046 & 0.0044 & 0.0044 & 0.0037 & 0.0027 \\ 22 & \mathbf{0 . 0 0 7 8} & 0.0073 & 0.0073 & 0.0068 & 0.0055 & 0.0039 \\ 27 & \mathbf{0 . 0 0 8 7} & 0.0084 & 0.0088 & 0.0083 & 0.0067 & 0.0039 \\ 32 & 0.0091 & \mathbf{0 . 0 0 9 1} & 0.0096 & 0.0094 & 0.0075 & 0.0045 \\ 37 & 0.0093 & \mathbf{0 . 0 0 9 5} & 0.0100 & 0.0100 & 0.0080 & 0.0050 \\ 42 & 0.0105 & 0.0110 & \mathbf{0 . 0 1 1 2} & 0.0113 & 0.0093 & 0.0062 \\ 47 & 0.0126 & 0.0136 & \mathbf{0 . 0 1 3 2} & 0.0133 & 0.0115 & 0.0087 \\ 52 & 0.0160 & 0.0179 & 0.0172 & \mathbf{0 . 0 1 7 1} & 0.0155 & 0.0122 \\ 57 & 0.0205 & 0.0240 & 0.0232 & \mathbf{0 . 0 2 2 6} & 0.0218 & 0.0182 \\ 62 & 0.0301 & 0.0344 & 0.0339 & 0.0324 & \mathbf{0 . 0 2 9 1} & 0.0277 \\ 67 & 0.0467 & 0.0502 & 0.0508 & 0.0475 & \mathbf{0 . 0 3 7 1} & 0.0410 \\ 72 & 0.0697 & 0.0728 & 0.0752 & 0.0707 & 0.0524 & 0.0630 \\ 77 & 0.1012 & 0.1047 & 0.1104 & 0.1052 & 0.0782 & \mathbf{0 . 0 9 8 8} \\ 82 & 0.1409 & 0.1498 & 0.1552 & 0.1528 & 0.1178 & \mathbf{0 . 1 4 0 2} \\ 87 & 0.1906 & 0.2144 & 0.2116 & 0.2188 & 0.1784 & 0.1860\end{array}$

Source: The author used official death and population counts in the area now identified as the Republic of Ireland. Because of pronounced age rounding, King's Method was used to estimate mortality rates at each age (King, 1909). The ages shown are generally the rates at 'pivotal' ages under the method but, where necessary, oscillatory interpolation was used to estimate rates at other ages. Ireland introduced compulsory registration of deaths from 1867 and had reasonable accurate censuses every decade or so since that time so it is possible to get a reasonably good estimate of mortality rates since 1871 . 
the ability to hold two opposed ideas in the mind at the same time and still retain the ability to function (The Crack-Up, 1936) - to continue.

The next paper is by Mariachiara Di Cesare \& Mike Murphy and shows the advantage of a first rate intelligence: through detailed case studies they show that, inter alia, mortality projections by individual cause of death can be improved by using period-based models for those causes of death that are primarily driven by calendar year effects and by employing cohort-based models when the underlying driving factor is primarily related to long-term past exposures that are changing in time.

\section{The Last Four Papers}

The last four papers treat different themes.

First is Eugene Milne's proposal of a new mathematical model of ageing and mortality. The model is a simple but well-motivated model of individual mortality risk that, he shows, is capable of reproducing mortality curves of human populations and those of other species when heterogeneity of risk within the population is captured by parameter variability. The model is in the classic tradition of mathematical and actuarial science and, from its capability to reproduce empirical characteristics of mortality curves over time, demands to be considered alongside such time-proven laws as, say, the Beard model, the Makeham-Perks and the Makeham-Beard model when fitting and interpreting mortality models of individual risk in a heterogeneous population (see, for instance, Richards (2008) for a recent application of this approach).

Gordon Woo and colleagues consider how mortality risk might be modelled on a prospective basis, in a parallel to how catastrophe risk is currently modelled. Eschewing the dominant approach of statistically modelling past mortality data and then trying to project rates into the future, they outline all the factors that affect future rates and attempt to model each factor stochastically, from advances in geroscience to new drug discoveries to changes in personal lifestyles. While Gordon Woo and colleagues take an optimistic view of the future of longevity risk measurement and, in particular, the attainability of models accurate enough to estimate credibly the $99.5 \%$ value-at-risk capital requirements under Solvency II, their thought-provoking discussion of the factors left me less convinced of their mathematical tractability.

Bridget Browne and colleagues address themselves directly to the problem of developing a stochastic model of future mortality variability that might determine the capital required for an annuity portfolio to satisfy the requirements of the regulator. Their proposed model can be bolted on to any deterministic model of future expected mortality rates. They recommend, with supporting rationale, an absolute minimum level of volatility (not be less than $2 \%$ ) but model with levels double or more of the minimum level so the sensitivity of reserves to the volatility assumed can be appreciated. This 
paper is of significant practical importance to actuaries developing such models.

Stephen Richards provides the final paper, in which he considers some issues that arise for actuaries in applying some of the insights gained from presentations at the conference. In particular, he considers the challenges of projecting mortality by cause of death, data problems when the original motivation for collecting the data was not primarily for mortality investigation, and a discussion of Eugene Milne's model from an actuarial perspective.

\section{Concluding Remarks}

One of the most fertile streams in the conference was exploring the interconnections between individual risk characteristics and aggregate population mortality as biomedical and health researchers studying mortality at an individual level sought common ground with demographers and actuaries. Before the conference, the link between one and the other was, I lazily thought, adequately captured in the cohort effect that has been incorporated into many actuarial models and demographic projections in recent years.

Evidence in biomedical literature supports the view that risk characteristics across the life course, and especially in early infancy, has an impact on later life mortality. This suggests that mortality models would be enhanced by modelling the life course, proxied by year of birth. On the other hand, evidence from demographers shows that health and mortality crises in populations cast no shadow over later mortality records, so suggesting that traditional mortality modelling by calendar year remains satisfactory. The two apparently opposing views can be reconciled if it is supposed that population mortality is sufficiently heterogeneous, with the mix changing sufficiently over time, to mask the detection of later life effects of even the most severe environmental crisis early in life. Given this insight, actuaries and demographers must pay particular attention to the changing mix in the population of subgroups with known mortality differentials. This observation, stressed in pretty much the first lecture in every first course in mortality statistics, is hardly blinding but still, remarkably, it is not done at a population level.

Consider the lesson to be learned from the smoking habit. Smoking, as Diana Kuh and colleagues' paper reminds us, doubles the risk of death for those who have developed the habit. This level of elevated mortality risk is the same order of magnitude as that experienced in one of the worse famines in the last couple of centuries (see earlier), yet the habit was allowed to spread largely unchecked over decades. Even now, we do not know what overall effect it has had on population mortality in the UK over the twentieth century and what patterns in past mortality rates can be attributed to a changing prevalence or intensity of the smoking habit. 
The first paper in this issue also reminds us of the role that individual actuaries played in the past in uncovering individual risk factors. Portfolio of lives that actuaries monitor can be seen as longitudinal mortality studies of relatively large sample sizes with exceptionally high quality data. As such, actuaries are best placed to detect early risk factors and estimate their significance. We should ensure that extra information is collected on each life so that such studies can fulfil their potential to advance our knowledge of risk factors - not for current rating purposes but solely in the interests of science. The smoking example highlights that there is much scope for improvement here: it was not until the early 1980s that life offices in these isles rated smoking as a risk in premium rates and it was not until the early 1990s that the UK profession completed a study into the magnitude of the mortality risk (CMI Bureau, 1992), lagging the practice in North America by a decade and a half (Cowell \& Hirst, 1980; Chittenden et al., 1985).

For all the institutions that monitor and manage the economy to maximise real GDP per capita, the more valued objective of adding years to life is left to nobody to manage. Even actuaries' interest in mortality improvements tend, as Stephen Richards remarked at the conference, to be inversely proportional to long term interest rates. Actuaries have played a role in the prosperity of the nation by helping to maintain the financial soundness of provident institutions but maybe there is scope also to help lengthen lives.

We have a surprisingly vague idea on how 0.3 years were added years to life each calendar year over the twentieth century and we certainly do not know how much more it could have been given simple initiatives (e.g., banning smoking in public places earlier). If it is not monitored then it is most unlikely to be optimised. Adding years to lives is barely monitored now and negligible resources are devoted to manage it. As such, it is difficult to see how the nation can approach actuarial escape velocity. However, by getting even more information from the vast longitudinal mortality experiences that actuaries help manage and monitor, the actuarial profession can play a larger role in helping achieve what is possible with the available resources. Perhaps the tagline of the profession of 'making financial sense of the future' can be changed to be 'live long and prosper'.

\section{REFERENCES}

BARKer, D.J.P. (1994). Mothers, babies, and disease in later life. British Medical Journal Publishing Group, London.

BARKer, D.J.P. (1998). Mothers, babies and health in later life. 2nd edn, Churchill Livingstone, Edinburgh.

BARker, D.J.P. (ed.) (2001). Fetal origins of cardiovascular and lung disease. Marcel Dekker Inc, New York. 
BArker, D.J.P., Osmond, C. \& LAw, C.M. (1989). The intrauterine and early postnatal origins of cardiovascular disease and chronic bronchitis. Journal of Epidemiology and Community Health, 43, 237-240.

Boyle, P.P. \& Ó GrÁDA, C. (1986). Fertility trends, excess mortality, and the Great Irish Famine. Demography 23(4), 543-562.

Carey, J.R. (2003). Longevity: the biology and demography of life span. Princeton University Press, Princeton.

Chittenden, C., Cowell, M.J., Miller, G.H. \& Myers, R.J. (1985). Smoking and sex mortality differentials: panel discussion. Record of the Society of Actuaries 11(4A), 18991927.

CMI Bureau (1992). Press release: smokers and non-smokers - a mortality study. 14th October 1992.

Cowell, M.J. \& Hirst, B.L. (1980). Mortality differences between smokers and nonsmokers. Transactions of the Society of Actuaries XXXII, 185-261.

De Grey, A.D.N.J. (2004). Escape velocity: why the prospect of extreme human life extension matters now. Book review in PLoS Biology, 2(6), 723-726.

Derrick, V.P.A. (1927). Observation on (1) error on age on the population statistics of England and Wales and (2) the changes of mortality indicated by the national records (with discussion). Journal of the Institute of Actuaries, 58, 117-159.

Economist, The (2004). The Economist Intelligence Unit's quality of life index. In The World in 2005. The Economist Newspaper Limited, London.

English Life Table 12 (1961). Registrar General's Decennial Supplement, England \& Wales 1961 Life Tables. HMSO, London.

Finch, C.E. \& CRimmins, E.M. (2004). Inflammatory exposure and historical changes in human life-spans. Science, 305, 1736-1739.

Fitzgerald, F.S. (1936). The Crack-Up. Part 1 was originally published in Esquire in February 1936 and is now available in many collections such as The crack-up with other pieces and stories by F. Scott Fitzgerald, Penguin Books, 1965.

Gluckman, P., Beedle, A. \& Hanson, M. (2009). Principles of evolutionary medicine. Oxford University Press, Oxford.

Gluckman, P.D. \& Hanson, M.A. (eds.) (2006). Developmental origins of health and disease. Cambridge University Press, Cambridge.

KING, G. (1909). On a new method of constructing and of graduating mortality and other tables. Journal of the Institute of Actuaries, XLIII, 109-184.

Macdonald, C. (2008). Scoping Mortality Research (Report of the Mortality Research Steering Group). Presented to the Institute of Actuaries, Staple Inn, 22nd September 2008, and forthcoming in the British Actuarial Journal.

Mair, W., Goymer, P., Pletcher, S.D \& Partridge, L. (2003). Demography of dietary restriction and death in Drosophila. Science, 301, 1731-1733.

Mokyr, J. \& Ó GrádA, C. (2002). What do people die of during famines? The Great Irish Famine in comparative perspective. European Review of Economic History, 6(3), 339364.

Office of Population Censuses and Surveys (1995). National Population Projections, 1992based. Series PP2, No. 18. HMSO, London.

Ó GrádA, C. (2007). Making famine history. Journal of Economic Literature, XLV (March), 5-38.

Richards, S. (2008). Applying survival models to pensioner mortality data. British Actuarial Journal, 14(II), 257-326.

Richards, S.J., Ellam, J.R., Hubbard, J., Lu, J.L.C., Makin, S.J. \& Miller, K.A. (2007). Two-dimensional mortality data: patterns and projections. British Actuarial Journal, 13(III), 479-555.

Richards, S.J., Kirkby, J.G. \& Currie, I.D. (2006). The importance of year of birth in twodimensional mortality data. British Actuarial Journal, 12(1), 5-38. 
United Nations (2005). Human Development Report 2004: Cultural liberty in today's diverse world. United Nations Development Programme.

Vaupel, J.W., Carey, J.R. \& Christensen, K. (2003). It's never too late. Science, 301, 16791680.

Willets, R.C. (2004). The cohort effect: insights and explanations. British Actuarial Journal, 10(IV)(48), 833-877.

Willets, R.C., Gallop, A.P., Leandro, P.A., Lu, J.L.C., MacDonald, A.S., Miller, K.A., Richards, S.J., Robjohns, N., Ryan, J.P. \& Waters, H.R. (2004). Longevity in the 21 st century. British Actuarial Journal, 10(IV)(48), 685-832.

Wilmoth, J.R. (1997). In search of limits. In: K. WAChter \& C. Finch (eds.). Between Zeus and the Salmon: the Biodemography of Longevity. National Academic Press, Washington. 